\title{
Tomato, tocopherols and the level of ige
}

\author{
M. F. Godoy ${ }^{1}$, R. Asis $^{2,4}$, F. O. Carrari ${ }^{3,4}$, N. H. Slobodianik ${ }^{5}$ and E. M. Insani ${ }^{1}$ \\ ${ }^{1}$ Instituto Tecnología de Alimentos - INTA, ${ }^{2}$ Facultad de Ciencias Químicas, Universidad Nacional de Córdoba, ${ }^{3}$ Instituto \\ de Biotecnología - INTA, ${ }^{4}$ CONICET, Buenos Aires and ${ }^{5}$ Facultad de Farmacia y Bioquímica, Universidad de Buenos \\ Aires and Argentina
}

This study was aimed to evaluate the effect of tomato and tocopherols (vitamin E) intake on IgE levels in GALT (gut associated lymphoid tissues). An experimental model of secondary allergy to protein malnutrition was used. The effect on IgE + B cells in Lamina Propria of intestinal villi was evaluated by Indirect Immuno- Fluorescence and IgE level in intestinal fluid by ELISA (Bethyl Laboratories). Weanling rats of Wistar strain were fed a protein-free diet until they lost $25 \%$ of their initial body weight. This diet developed an allergic state $^{(1)}$. Re-feeding was performed by the administration of an experimental diet containing $20 \%$ casein as the only source of protein (Renourished group $=\mathbf{R})$. Other groups received this experimental diet plus oral administration of $a)$ fresh tomato $(\mathbf{R}+\mathbf{T}): 3.31 \mu \mathrm{g} / \mathrm{g} \mathrm{rat} / \mathrm{day}$, equivalent to $230 \mathrm{~g} /$ day for an adult man of $70 \mathrm{~kg} ; b)$ a tocopherols mix $(\alpha, \beta, \gamma, \delta)(\mathbf{R}+\mathbf{m i x} \mathbf{T p h})$ equivalent to those present in tomato fruit; $c$ ) gamma- tocopherol $(\mathbf{R}+\mathbf{G}): 0.21 \mu \mathrm{g} / \mathrm{g}$ rat/day, equivalent to $80 \mathrm{x}$ to those present in tomato fruit. All compounds were added to drinking water during 35 days. The animal protocol was approved by the Ethical Committee of the University of Buenos Aires. The small intestine was removed, the intestinal fluid collected and further processed by Saint-Marie's technique ${ }^{(2)}$. The abundance of tocopherols isomers in tomato (cv. M82) was measured by HPLC with UV-Vis diode array and fluorescence detectors.

Results showed that Lamina Propria of intestinal villi from the $\mathbf{R}+\mathbf{T}$ group presented higher $\%$ of $\operatorname{IgE}+\mathrm{B}$ cells compared to those from the $\mathbf{R}$ group $(99 \pm 8$ vs $62 \pm 11)$. Intake of tocopherols mixture in low concentration and gamma-tocopherol in higher concentration reverted that situation lowering the levels to $31 \pm 6$ and $38 \pm 5$, respectively (Fig.). A similar pattern was observed in intestinal fluid (Table) but without significant statistical difference $(p>0.05)$.

Table. IgE in intestinal fluid. No statistical difference $(p>0.05)$

\begin{tabular}{lcc}
\hline & \multicolumn{2}{c}{$\operatorname{IgE}(\mathrm{pg} / \mathrm{ml})$} \\
\cline { 2 - 3 } Treatments & Mean & $\mathrm{SE}$ \\
\hline $\mathrm{R}$ & 8.0 & 1.3 \\
$\mathrm{R}+\mathrm{T}$ & 8.4 & 0.9 \\
$\mathrm{R}+$ mix Tph & 6.7 & 0.7 \\
$\mathrm{R}+\mathrm{G}$ & 6.9 & 1.1 \\
\hline
\end{tabular}

SE: Standard error

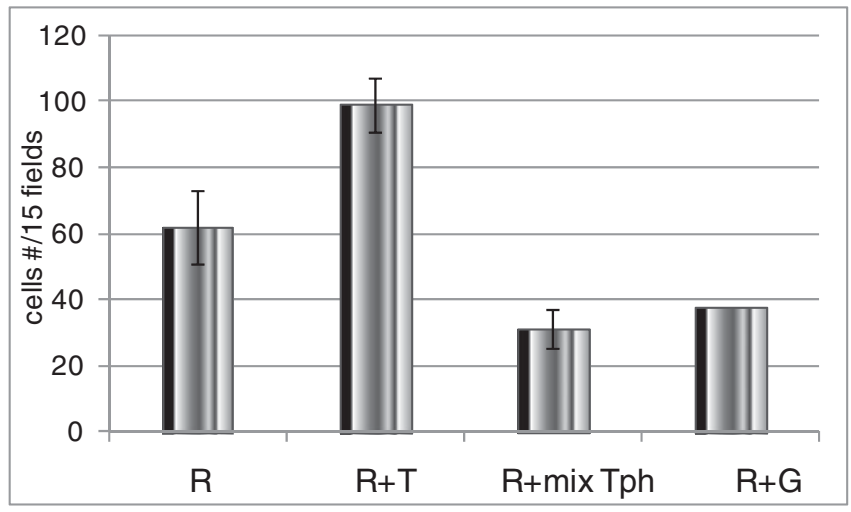

Figure. IgE + B cells in intestinal villi.

These results suggest that possible allergenic responses triggered by tomato intake could be alleviated by tocopherols.

1. Insani, EM (2010) PhD Thesis, University of Buenos Aires.

2. Saint Marie G (1962) J Histochem. Cytochem. 10, 250-256. 